\title{
chaOPEN
}

\section{Hospital outcomes of children admitted to intensive care in British Columbia via interfacility transfer versus direct admission from 2015 to 2017: a descriptive analysis}

\author{
Jollee S.T. Fung MD, Sean Wong BSc, Srinivas Murthy MDCM, Fiona Muttalib MDCM
}

Abstract

Background: Pediatric intensive care relies on having experienced and effective transport systems to transfer critically ill children to the appropriate centre for care. Our aim was to compare hospital outcomes among children admitted directly to a pediatric intensive care unit (PICU) with those of children transferred from another facility.

Methods: We conducted a descriptive study using electronic medical records and the PICU database from the BC Children's Hospital. Patients admitted to the PICU from January 2015 to December 2017 were included. We excluded patients who were admitted electively, were admitted for recovery postoperatively, or had inconsistent or out-of-range addresses. We compared hospital mortality rates, use of mechanical ventilation within 24 hours of admission and length of PICU stay between children admitted directly from the BC Children's Hospital emergency department and those transferred from a referring institution.

Results: During the study period, there were 870 unique admissions comprising 386 direct admissions and 484 transferred patients. Transported patients were younger, were more critically ill on presentation and required longer stays. The proportions of children who died and of children who required mechanical ventilation within 24 hours of admission were higher in the transported group than in the group admitted directly from the emergency department (8.3\% v. 3.9\%, $p=0.008$, and $75.8 \%$ v. $58.0 \%, p<0.001$, respectively).

Interpretation: Mortality rate and use of intensive care resources were higher among children who were transported. Further research is needed to examine the key factors driving the differences in outcomes, including the severity of illness on first presentation, transport team composition, and transport distance and duration.

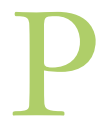
ediatric intensive care across the world is typically delivered through a centralized model in which specialized resources, including personnel and equipment, are concentrated in specific regions, often at tertiary centres. This model relies on having experienced and effective transport systems to transfer critically ill children to the appropriate centre for care. Existing literature has suggested that the centralization of pediatric intensive care services to high-volume centres is associated with decreased mortality in pediatric populations. ${ }^{1-7}$

With this centralization, it has also been shown that, compared with direct in-hospital admissions, children who were transported from other hospitals were more critically ill at pediatric intensive care unit (PICU) admission, had longer hospital length of stay and had higher use of intensive care-specific therapies, such as mechanical ventilation and inotropic infusions. ${ }^{8-12}$ Risk-adjusted mortality rates based on severity of illness at admission did not differ significantly between the groups. ${ }^{8,10,13}$

Canada has the second largest geographic area in the world and has nearly 3 million children living in areas without direct access to these specialized pediatric critical care services; about $20 \%$ of the population lives outside of urban centres. ${ }^{12}$ In British Columbia, the BC Children's Hospital PICU provides pediatric critical care support to children in $\mathrm{BC}$ and Yukon Territory.

There remains a knowledge gap in the epidemiology and differences in outcomes among children who require transport and those who present directly to the emergency department. The primary objective of this descriptive study was to explore the differences in patient outcomes (mechanical ventilation use within 24 hours of admission, PICU length of stay and hospital mortality) among critically ill children who were transported and children who were directly admitted from the emergency department.

\section{Competing interests: None declared.}

This article has been peer reviewed.

Correspondence to: Fiona Muttalib, fiona.muttalib@cw.bc.ca CMAJ Open 2021. DOI:10.9778/cmajo.20200263 


\section{Methods}

\section{Study design}

This was a retrospective cohort study comparing the characteristics and differences in patient outcomes between children who were transported to the PICU and those who were admitted directly from the emergency department.

\section{Setting}

The PICU at BC Children's Hospital is a 28-bed, level-1, medical, surgical and cardiac ICU with about 1100 admissions annually, providing intensive care to critically ill children across BC and Yukon Territory. It is the only level-1 PICU in the region. Children are admitted directly from the emergency department, from inpatient wards or from other hospitals. The process of transfer begins when the on-call intensivist at the PICU is consulted by a physician caring for a critically ill child at another hospital. Once a decision to transfer and admit to the PICU is made, a provincially run transport team is dispatched, with a number of fixed-wing, helicopter and ambulance-based transport teams available. The most common teams to be dispatched for a critically ill child are the infant transport team, comprising 2 paramedics with specialized training in advanced neonatal and pediatric care, or an adult critical care team, comprising 2 paramedics with specialized training in adult critical care and the capacity and skills to transport pediatric patients.

\section{Participants}

All patients admitted to the PICU from January 2015 to December 2017 with a residential address in BC or Yukon Territory were eligible for the study. BC Children's Hospital provides care for children from birth to age 18 years. Exclusion criteria included patients who were admitted electively, were admitted postoperatively, had more than 1 residential address or had an out-of-province (other than Yukon) residential address.

\section{Data sources}

Data were extracted from a database of patients requiring admission to the PICU (Virtual Pediatric Systems) and the electronic medical charts. Two authors independently abstracted the data (J.S.T.F. and S.W.) onto a Microsoft Excel file with patient identifiers removed. Data extraction was performed independently in duplicate for a random selection of 20 medical charts; no discrepancies were identified. The following data elements were collected: residential postal codes, age and weight at admission, admission diagnosis, admission source, transport mode, initial vital signs on admission, severity-of-illness score (Pediatric Risk of Mortality III [PRISM3]), length of PICU stay, use of mechanical ventilation at admission or within the first 24 hours, and mortality. PRISM3 is a validated composite score calculated using 17 physiologic variables collected on PICU admission to predict the risk of mortality. ${ }^{13-15}$

\section{Statistical analysis}

We used descriptive analyses to summarize the demographic characteristics of the study population. Continuous data were expressed as means and standard deviations for normal distri- bution, and medians and interquartile ranges (IQRs) for nonnormal distribution. We compared means using the Student $t$ test and medians using the Mann-Whitney $U$ rank-sum test. Categorical data were summarized as counts and proportions and compared using the $\chi^{2}$ test. Transport distances were 1 -way and calculated using an online tool ${ }^{16}$ by inputting residential postal codes of the patients and measuring distance by land or by crow (i.e., for air transport) to BC Children's Hospital as the reference point. We categorized admission diagnoses into 1 of the following: respiratory, cardiac, neurologic, gastrointestinal/surgical, infection/sepsis, endocrine, trauma/ burns/drowning, oncological, poison/overdose/other, and missing, using admission International Classification of Diseases, 10th Revision (ICD-10) codes.

The primary outcome was hospital mortality. Secondary outcomes were the use of mechanical ventilation within 24 hours of admission and length of stay in the PICU.

Patient encounters were excluded if there were unavailable or unusable data for any of the primary outcomes. This included patients with addresses that were missing, incomplete or inconsistent with the recorded transport modalities (i.e., using a fixed-wing aircraft for addresses within $50 \mathrm{~km}$ ).

The analysis was conducted using $\mathrm{R}$ version 3.6.1 ( $\mathrm{R}$ Core Team). Statistical significance was considered at a $p$ value less than 0.05 .

\section{Ethics approval}

Ethics approval was obtained from the University of British Columbia/Children's and Women's Health Centre of British Columbia Research Ethics Board.

\section{Results}

Over the 3-year study period, there were 870 unique eligible admissions with 386 direct admissions and 484 patients transported from another hospital. Baseline characteristics of the study population are shown in Table 1 . Patient age ranged from under 1 month to 21 years. Overall, patients who were transported from another hospital were younger (median age $32 \mathrm{mo}$, IQR 7-115 v. $52 \mathrm{mo}$, IQR $10-135$; $p=0.01$ ) than those admitted directly from the emergency department. Transported patients also had higher median PRISM3 scores (0.63, IQR 0.3-1.6 v. 0.49, IQR 0.3-1.0; $p<0.001)$ at admission to PICU than those directly admitted. A total of 82 patient encounters were excluded owing to missing data.

Among the diagnostic categories, there were similar rates of admission for respiratory, cardiac, gastrointestinal or surgical, infectious, endocrine, trauma and oncological causes between the direct admission group and the transported group. However, a higher proportion of admissions in the transported group were for poison or overdose-related conditions, comprising $6.0 \%$ of admissions in the transported group compared with $2.8 \%$ in the direct admission group $\left(\chi^{2}=4.14, p=0.04\right)$.

\section{Transported patients}

Of the 484 children transported, 8 children (1.7\%) had residential addresses in Yukon Territory, and the remainder 
Research

\begin{tabular}{|c|c|c|c|c|}
\hline \multirow[b]{2}{*}{ Characteristic } & \multicolumn{3}{|c|}{ No. $(\%)$ of patients* } & \multirow[b]{2}{*}{$p$ value } \\
\hline & $\begin{array}{c}\text { Total } \\
n=870\end{array}$ & $\begin{array}{l}\text { Admitted from the ED } \\
\qquad n=386\end{array}$ & $\begin{array}{l}\text { Transported from } \\
\text { referring hospital } \\
\quad n=484\end{array}$ & \\
\hline \multicolumn{5}{|l|}{ Sex } \\
\hline Male & $490(56.3)$ & $217(56.2)$ & $273(56.4)$ & $>0.9$ \\
\hline Female & $380(43.7)$ & $169(43.8)$ & $211(43.6)$ & $>0.9$ \\
\hline Age, mo, median (IQR) & $41(9-121)$ & $52(10-135)$ & $32(7-115)$ & 0.01 \\
\hline Weight, kg, median (IQR) & $15(8-35)$ & $16(9-36)$ & $14(7-31)$ & 0.04 \\
\hline PRISM3 risk score, median (IQR) & $0.63(0.3-1.1)$ & $0.49(0.3-1.0)$ & $0.63(0.3-1.6)$ & $<0.001$ \\
\hline \multicolumn{5}{|l|}{ Admission category } \\
\hline Respiratory & $360(41.4)$ & $168(43.5)$ & $192(39.7)$ & 0.3 \\
\hline Cardiac & $49(5.6)$ & $18(4.7)$ & $31(6.4)$ & 0.3 \\
\hline Neurologic & $156(17.9)$ & $59(15.3)$ & $97(20.0)$ & 0.08 \\
\hline Gastrointestinal or surgical & $13(1.5)$ & $5(1.3)$ & $8(1.7)$ & 0.9 \\
\hline Infections/sepsis & $60(6.9)$ & $32(8.3)$ & $28(5.8)$ & 0.2 \\
\hline Endocrine & $40(4.6)$ & $19(4.9)$ & $21(4.3)$ & 0.8 \\
\hline Trauma, burns or drowning & $89(10.2)$ & $39(10.1)$ & $50(10.3)$ & $>0.9$ \\
\hline Oncological & $15(1.7)$ & $7(1.8)$ & $8(1.7)$ & $>0.9$ \\
\hline Poison/overdose & $40(4.6)$ & $11(2.8)$ & $29(6.0)$ & 0.04 \\
\hline Other & $29(3.3)$ & $18(4.7)$ & $11(2.3)$ & 0.08 \\
\hline Missing & $19(2.2)$ & $10(2.6)$ & $9(1.9)$ & 0.6 \\
\hline \multicolumn{5}{|l|}{ Transport modality } \\
\hline Private vehicle & $249(28.6)$ & $248(64.2)$ & $1(0.2)$ & - \\
\hline Ambulance & $402(46.2)$ & $138(35.8)$ & $264(54.5)$ & - \\
\hline Helicopter & $41(4.7)$ & 0 & $41(8.5)$ & - \\
\hline Fixed-wing aircraft & $178(20.5)$ & 0 & $178(36.8)$ & - \\
\hline Distance, km, median (IQR) & - & - & 67.1 (32.9-274.2) & - \\
\hline
\end{tabular}

resided in $\mathrm{BC}$. The median estimated distance travelled by transported patients was 67.1 (IQR 32.9-274.2) km. Ambulance transport was used for $54.5 \%$ of the transports, fixedwing aircraft for $36.8 \%$ and helicopter for $8.5 \%$ of transports.

\section{Outcomes}

Compared with the patients directly admitted to the PICU, transported patients had a longer length of PICU stay $(2.43 \mathrm{~d}$, IQR 0.9-4.6 v. $1.60 \mathrm{~d}$, IQR $0.8-3.4 ; p<0.001$ ) and higher rates of mechanical ventilation at admission or within the first 24 hours $(75.8 \%$ v. $58.0 \% ; p<0.001)$, and a higher proportion $\operatorname{died}(8.3 \%$ v. $3.9 \% ; p=0.008)$ (Table 2$)$.

\section{Interpretation}

Compared with children directly admitted to the PICU from the BC Children's Hospital emergency department, children transported to the BC Children's Hospital PICU from another facility were younger, more acutely ill at admission by measures of PRISM3 risk of mortality and had longer PICU lengths of stay. A higher proportion of children who underwent interfacility transfer received mechanical ventilation within the first 24 hours of admission and died in hospital than patients admitted directly from the emergency department.

Although existing studies have been consistent in observing that transported critically ill pediatric patients were younger, were more acutely ill and used more intensive care resources, there remains conflicting findings in terms of crude mortality rate differences between direct admission and transport groups. Our study showed a significantly higher crude mortality rate in the transport group, consistent with the findings from similar analyses conducted in other provinces in Canada and a study evaluating the national PICU in New Zealand. ${ }^{10,12,17}$ Conversely, a retrospective study involving 20 PICUs in the United States showed no difference in the crude or risk-adjusted mortality rates among transported 
Table 2: Outcome comparisons according to source of admission among patients admitted to the pediatric intensive care unit

\begin{tabular}{|c|c|c|c|c|}
\hline Outcome & $\begin{array}{c}\text { Total } \\
n=870\end{array}$ & $\begin{array}{c}\text { Admitted from } \\
\text { the ED } \\
n=386\end{array}$ & $\begin{array}{l}\text { Transported } \\
\text { from referring } \\
\text { hospital } \\
n=484\end{array}$ & $p$ value \\
\hline PICU length of stay, d, median (IQR) & $1.88(0.8-4.1)$ & $1.60(0.8-3.4)$ & $2.43(0.9-4.6)$ & $<0.001$ \\
\hline Use of mechanical ventilation within 24 hours, no. (\%) & $591(67.9)$ & $224(58.0)$ & $367(75.8)$ & $<0.001$ \\
\hline
\end{tabular}

children versus direct admissions. ${ }^{8}$ Finally, a nationwide study in England and Wales found that the risk-adjusted mortality rate using severity-of-illness scores at first involvement of pediatric critical care teams was lower among transported patients than among those admitted directly to the PICU.?

These conflicting study results may relate to underlying differences in the pediatric critical care transport systems worldwide and limitations of currently available data. There exists a broad spectrum in the composition and skill set of transport teams, which may influence clinical outcomes. ${ }^{11,18}$ The median distance travelled varied greatly among the studies, with ranges from $35 \mathrm{~km}$ in the UK study to $383 \mathrm{~km}$ in an epidemiologic study of pediatric critical care transport in northern Canada. ${ }^{19}$ The needs of a Canadian transport system are likely to be very different from those of countries with a smaller geographic footprint.

Further research is needed to understand the complex interplay between available transport modalities; transport team compositions and skill sets; distances between residential addresses, initial hospital and receiving hospital; and transport duration. In additional, the vast geographical area of Canada allows for diverse enclaves of populations with different socioeconomic, cultural and racial compositions to be settled in specific regions. An analysis of patient outcomes in relation to geographic areas, socioeconomic status and regional burden of pediatric critical illness is warranted. Together, these data will be crucial for clinicians, administrators and policy-makers to better target transport system improvement to mitigate disparities in outcomes.

\section{Limitations}

There are several limitations to this study. First, data pertaining to the initial presentation and care received at the referring hospital and during transport were limited owing to the retrospective nature of this study. Specifically, pretransfer severityof-illness scores were not available; therefore, it is unknown whether differences in observed mortality among transported patients are related to differences in severity of illness at presentation, transport-specific factors or time to definitive management. In addition, transport team composition and skill set were not available for analysis; these factors have been shown to vary across Canada and to influence outcomes in the United Kingdom. ${ }^{11,18}$ The lack of recorded time from referral to PICU admission also limited our ability to interpret the effects of transport time on patient outcomes. Finally, transport distance was estimated based on distance from listed residential address to the final destination. Although this practice has been used in previous studies,, 12 it may not truly reflect the impact of total distance (e.g., home to initial hospital, referring hospital to receiving hospital) on patient outcomes.

\section{Conclusion}

Compared with children admitted directly from the BC Children's Hospital emergency department, patients requiring interfacility transport to the PICU had higher severity-of-illness scores at admission, and a greater proportion received mechanical ventilation at admission or within 24 hours. In addition, a greater proportion of children who underwent interfacility transfer died in hospital; however, this finding is limited by insufficient data surrounding their severity of illness at first presentation. This study highlights the need for further research to identify factors driving differences in outcomes, including severity of illness at first presentation, transport team composition, and transport distance and duration.

\section{References}

1. Gemke RJBJ, Bonsel GJ, Bijlmer RPGM, et al. Comparative assessment of pediatric intensive care: a national multicenter study. Crit Care Med 1995;23: 238-45.

2. Pearson G, Shann F, Barry P, et al. Should paediatric intensive care be centralised? Trent versus Victoria. Lancet 1997;349:1213-7.

3. Pollack MM, Alexander SR, Clarke N, et al. Improved outcomes from tertiary center pediatric intensive care: a statewide comparison of tertiary and nontertiary care facilities. Crit Care Med 1991;19:150-9.

4. Karamlou T, Vafaeezadeh M, Parrish AM, et al. Increased extracorporeal membrane oxygenation center case volume is associated with improved extracorporeal membrane oxygenation survival among pediatric patients. 7 Thorac Cardiovasc Surg 2013;145:470-5.

5. Tasker RC, Fleming TJ, Young AE, et al. Severe head injury in children: intensive care unit activity and mortality in England and Wales. Br 7 Neurosurg 2011;25:68-77.

6. Tilford JM, Simpson PM, Green JW, et al. Volume-outcome relationships in pediatric intensive care units. Pediatrics 2000;106:289-94.

7. Thompson DR, Clemmer TP, Applefeld JJ, et al. Regionalization of critical care medicine: task force report of the American College of Critical Care Medicine. Crit Care Med 1994;22:1306-13.

8. Gregory CJ, Nasrollahzadeh F, Dharmar M, et al. Comparison of critically ill and injured children transferred from referring hospitals versus in-house admissions. Pediatrics 2008;121:e906-11.

9. Ramnarayan P, Thiru K, Parslow RC, et al. Effect of specialist retrieval teams on outcomes in children admitted to paediatric intensive care units in England and Wales: a retrospective cohort study. Lancet 2010;376:698-704.

10. Moynihan K, McSharry B, Reed P, et al. Impact of retrieval, distance traveled, and referral center on outcomes in unplanned admissions to a national PICU. Pediatr Crit Care Med 2016;17:e34-42.

11. Ramnarayan P, Dimitriades K, Freeburn L, et al. Interhospital transport of critically ill children to PICUs in the United Kingdom and Republic of Ireland: analysis of an international dataset. Pediatr Crit Care Med 2018;19: e300-11. 
12. Sample M, Acharya A, O'Hearn K, et al. The relationship between remoteness and outcomes in critically ill children. Pediatr Crit Care Med 2017;18:e514-20.

13. Pollack MM, Patel KM, Ruttimann UE. PRISM III: an updated pediatric risk of mortality score. Crit Care Med 1996;24:743-52.

14. Pollack MM, Holubkov R, Funai T, et al. The Pediatric Risk of Mortality Score: update 2015. Pediatr Crit Care Med 2016;17:2-9.

15. PRISM III Calculator. Salt Lake City (UT): CPCCRN. Available: www.cpccrn. org/calculators/prismiiicalculator (accessed 2019 Nov. 3).

16. Distance between Canadian postal codes. Free Map Tools. Available: www.freemaptools.com/distance-between-canada-postcodes.htm (accessed 2019 Dec. 19).

17. Kawaguchi A, Saunders LD, Yasui Y, et al. Effects of medical transport on outcomes in children requiring intensive care. F Intensive Care Med 2020;35:889-95.

18. Kawaguchi A, Gunz A, De Caen A. Cross-sectional survey of Canadian pediatric critical care transport. Pediatr Emerg Care 2019;35:32-7.

19. Kawaguchi A, Nielsen CC, Guerra GG, et al. Epidemiology of pediatric critical care transport in Northern Alberta and the Western Arctic. Pediatr Crit Care Med 2018;19:e279-85.

Affiliations: Faculty of Medicine (Fung), University of British Columbia, Vancouver, BC; Schulich School of Medicine \& Dentistry (Wong), University of Western Ontario, London, Ont.; Division of Critical Care, Department of Pediatrics (Murthy, Muttalib), University of British Columbia, Vancouver, BC; Centre for Global Child Health, Hospital for Sick Children (Muttalib), Toronto, Ont.
Contributors: Srinivas Murthy designed the study with input from Fiona Muttalib. Jollee Fung and Sean Wong extracted the data and performed the data analyses, with input from all authors on interpretation and conclusions. Jollee Fung drafted the manuscript. All authors revised the manuscript critically for content, approved the final version to be published and agreed to be accountable for the work.

Funding: The authors received no financial support for the research, authorship or publication of this article.

Content licence: This is an Open Access article distributed in accordance with the terms of the Creative Commons Attribution (CC BY-NC-ND 4.0) licence, which permits use, distribution and reproduction in any medium, provided that the original publication is properly cited, the use is noncommercial (i.e., research or educational use), and no modifications or adaptations are made. See: https://creativecommons.org/licenses/ by-nc-nd/4.0/

Data sharing: Data may be available from the corresponding author on request.

Supplemental information: For reviewer comments and the original submission of this manuscript, please see www.cmajopen.ca/content/9/2/ E602/suppl/DC1. 